J. Clin. Chem. Clin. Biochem.

Vol. 25,1987 , pp. $865-868$

(C) 1987 Walter de Gruyter \& Co. Berlin - New York

\title{
Serum Proteins in Liver Cirrhosis: Effects of Shunt Surgery
}

\author{
By B. Joelsson, A. Alwmark, P. Gullstrand, S. Bengmark
}

Department of Surgery, University Hospital Lund, Lund, Sweden and

\section{B. Hultberg}

Department of Clinical Chemistry, University Hospital Lund, Lund, Sweden

(Received September 1, 1987)

Summary: The serum protein patterns of 38 patients with alcoholic liver cirrhosis were studied and compared with those of 15 patients with cryptogenic cirrhosis and of 18 normal volunteers. Serum prealbumin and albumin were significantly lowered in alcoholic liver cirrhosis in comparison with the normals. In liver cirrhosis, the four acute phase reactants, $\alpha_{1}$-antiproteinase, orosomucoid, haptoglobin and caeruloplasmin, showed a pattern in serum, in which $\alpha_{1}$-antiproteinase was increased, orosomucoid and haptoglobin were decreased, and caeruloplasmin was normal. Immunoglobulins G, A and $M$ were significantly elevated. IgA was significantly more elevated in patients with alcoholic disease than in patients with cryptogenic cirrhosis. The construction of a surgical portal-systemic shunt resulted in a significant decrease in serum concentrations of the acute phase reactants, while prealbumin, albumin and immunoglobulins were unaffected.

\section{Introduction}

Liver cirrhosis with portal hypertension is accompanied by changes in the concentration of proteins in serum $(1,2)$. A fall in albumin concentration has been shown to be related to the patient's life expectancy (3). Thus, it may be important to avoid further derangements in serum proteins when instituting therapy for bleeding secondary to the portal hypertension. Interposition meso-caval shunt ${ }^{1}$ ) surgery results in a reduction of portal blood flow to the liver and increased portal-systemic shunting. The inability of a portal-systemic shunt to prolong survival (4) might be explained by this reduction of nutrient blood flow to the liver causing further serum protein changes.

The present study was performed on patients with liver cirrhosis, portal hypertension and bleeding oesophageal varices, who where possible candidates for

\footnotetext{
1) Surgical shunt created for passage of venous blood from the superior mesenteric vein to the caval vein = mesentericocaval (meso-caval) shunt.
}

a meso-caval shunt or had undergone shunt surgery. We wanted to elucidate the extent to which these patients show derangements in serum proteins compared with healthy controls, and whether the serum protein pattern is influenced by a meso-caval shunt that reduces nutrient hepatic blood flow.

\section{Materials and Methods}

Serum protein patterns were analysed in 38 nonoperated patients with biopsy-proven alcoholic cirrhosis and a history of endoscopically verified bleeding oesophageal varices. For comparison, 15 nonoperated patients with cryptogenic cirrhosis and 18 normal volunteers were examined. These subjects did not differ statistically from the patients with alcoholic liver cirrhosis in sex or age distribution. Standard serum liver tests in the patients are shown in table 1.

The serum protein pattern was studied in ten patients with liver cirrhosis who were investigated before, and six to twelve months following, the construction of an interposition meso-caval shunt. A $14 \mathrm{~mm}$ Gore-Tex graft was used. Six of these patients had alcoholic, two cryptogenic and two primary biliary cirrhosis. None of these patients had clinically obvious ascites before or after the meso-caval shunt. 
Preoperatively the patients were admitted in a bleeding-free interval for routine examination. Portal hypertension, defined as a portal pressure exceeding $25 \mathrm{~cm}$ of water above atmospheric pressure, was found by portal pressure monitoring through a percutaneously introduced transhepatic portal catheter. In the operated patients, the patency of the meso-caval shunt was confirmed on angiography.

Following at least four days of alcoholic abstincence, with regular hospital food containing 80 gram of protein, overnight fasting blood samples were obtained from an antecubital vein. Serum bilirubin levels were analysed by the method of Nosslin (5). Serum catalytic activity concentrations of alanine aminotransferase $e^{2}$, alkaline phosphatase ${ }^{2}$ ), aspartate aminotransferase ${ }^{2}$ ) and $\gamma$-glutamyl transferase ${ }^{2}$ ) were assayed according to the Committee of Enzymes of the Scandinavian Society of Clinical Chemistry and Clinical Physiology $(6,7)$. Immunoassay methods as described by Laurell ( 8 ) were used to determine the serum proteins, prealbumin, albumin, $\alpha_{1}$ antiproteinase, orosomucoid, haptoglobin, caeruloplasmin and the immunoglobins $G, A$ and $M$ (IgG, IgA, IgM).

A typical pattern of acute phase proteins was defined according to Carlson \& Eriksson (9): $\alpha_{1}$-antiproteinase concentration minus orosomucoid concentration $\geqslant 5 \%$, and $\alpha_{1}$-antiproteinase concentration minus haptoglobin concentration $\geqslant 20 \%$.

Statistical evaluation was performed using the Mann Whitney rank sum test for unpaired data and the Wilcoxon signed rank test for paired data. A p-value $<0.05$ was considered significant.

\section{Results}

Serum proteins in alcoholic cirrhosis (tab. 2)

Serum prealbumin concentrations were significantly lower in the patients when compared with the reference population. All cirrhotic prealbumin values, except one, were below the inferior reference limit. Serum albumin concentrations were significantly lowered in the patients, with $84 \%$ of the values below the inferior reference limit.

The four acute phase reactants showed different patterns. $\alpha_{1}$-Antiproteinase was significantly elevated while orosomucoid and haptoglobin were significantly decreased. Caeruloplasmin was normal in most patients. The pattern of acute phase reactants indicative of liver disease as defined by Carlson \& Eriksson (9) was present in $72 \%$ of the cases.

\section{2) Enzymes:}

Alanine aminotransferase ( $L$-alanine-2-oxoglutarate aminotransferase EC 2.6.1.2).

Alkaline phosphatase (orthophosphoric monoester phosphohydrolase, alkaline optimum EC 3.1.3.1).

Aspartate aminotransferase ( $L$-aspartate-2-oxoglutarate aminotransferase EC 2.6.1.1).

$\dot{\gamma}$-Glutamyltransferase (( $\gamma$-glutamyl)-peptide: amino acid $\gamma$ glutamyl transferase EC 2.3.2.2).
The three immunoglobulins were all significantly elevated in the patients; IgG and IgA being the most frequently abnormal.

Serum proteins in cryptogenic cirrhosis (tab. 2)

These patients showed the same pattern as the subjects with alcoholic cirrhosis, except for $\operatorname{IgA}$, which was significantly more elevated in the latter.

Effects of a meso-caval shunt on serum proteins (tab. 3)

The prealbumin and albumin, produced by the liver, were not affected. Furthermore, immunoglobulins did not change significantly. The acute phase reactants, however, all decreased significantly following shunt surgery.

\section{Discussion}

A meso-caval shunt does not seem to influence hepatic protein production within six to twelve months, since prealbumin and albumin serum concentrations are unaffected postoperatively. The shunt usually diminishes ascites production and subsequently the loss of proteins into the peritoneal cavity is reduced. This might obscure serum changes due to diminished hepatic protein production. However, none of these patients had clinically obvious ascites before or after the meso-caval shunt.

Cirrhotic patients usually exhibit increased serum concentrations of $\alpha_{1}$-antiproteinase, and decreased concentrations of orosomucoid and haptoglobin, while caeruloplasmin is normal (9). The low concentrations of serum haptoglobin found in liver cirrhosis are probably at least partly due to the increased breakdown of erythrocytes in the enlarged spleen of patients with portal hypertension (10). An interesting observation is the significant fall in serum concentrations of the four acute phase reactants following shunt surgery. Increased shunting of endotoxins from the gut into the general circulation might theoretically cause release of interleukin-1 from activated macrophages, with ensuing induction of hepatic production of the acute phase reactants $(11,12)$. Possibly, the diminished nutrient portal blood flow to the liver, following shunt surgery, counteracts the expected increase and causes the decreased serum concentrations by reducing hepatic production. 
Tab. 1. Serum liver tests in the cirrhotic patients. Median and range.

\begin{tabular}{llll}
\hline & Alcoholic cirrhosis & Cryptogenic cirrhosis & Reference range \\
\hline Number of patients & 38 & 15 & \\
Number of men & 33 & 6 & $64(33-76)$ \\
Age (years) & $57(30-71)$ & $25.5(10-500)$ & $3-20$ \\
Bilirubin $(\mu$ mol/l) & $25(10-136)$ & $11.1(2.4-39.0)$ & $0.8-4.6$ \\
Alkaline phosphatase $(\mu \mathrm{kat} / \mathrm{l})$ & $5.0(2.9-13.0)$ & $3.2(0.2-8.7)$ & $<1.0$ \\
$\gamma$-Glutamyltransferase $(\mu \mathrm{kat} / \mathrm{l})$ & $2.4(0.6-7.7)$ & $1.2(0.4-3.1)$ & $<0.7$ \\
Aspartate aminotransferase $(\mu \mathrm{kat} / \mathrm{l})$ & $0.8(0.4-5.3)$ & $0.6(0.2-2.0)$ & $<0.7$ \\
Alanine aminotransferase $(\mu \mathrm{kat} / \mathrm{l})$ & $0.3(0.1-2.4)$ & & \\
\hline
\end{tabular}

Tab. 2. Serum proteins $(g / l)$ in normal subjects $(n=18)$ and in patients with alcoholic $(n=38)$ or cryptogenic $(n=15)$ cirrhosis. Median and range.

\begin{tabular}{llll}
\hline & Normal & Alcoholic & Cryptogenic \\
\hline Prealbumin & $0.30(0.19-0.37)$ & $0.10(0.05-0.21)^{*}$ & $0.10(0.09-0.21)^{*}$ \\
Albumin & $42(37-46)$ & $33(17-44)^{*}$ & $36(20-44)$ \\
a -Antiproteinase & $1.4(1.2-1.7)$ & $2.0(0.4-4.0)^{*}$ & $1.7(1.1-2.4)^{*}$ \\
Orosomucoid & $0.9(0.7-1.1)$ & $0.6(0.2-2.6)^{*}$ & $0.7(0.3-1.3)$ \\
Haptoglobin & $1.0(0.3-1.7)$ & $0.6(0.0-1.6)^{*}$ & $0.4(0.0-1.7)^{*}$ \\
Caeruloplasmin & $0.3(0.2-0.5)$ & $0.3(0.2-0.6)$ & $0.3(0.3-0.6)$ \\
IgG & $9.8(6.2-13.6)$ & $22.5(11.0-32.2)^{*}$ & $21.5(11.7-31.6)^{*}$ \\
IgA & $1.8(0.7-2.8)$ & $4.1(1.2-16.4)^{*}$ & $2.5(0.4-9.7)^{* *}$ \\
IgM & $1.4(0.6-2.2)$ & $1.9(0.6-5.7)^{*}$ & $1.7(1.1-4.6)$ \\
\hline
\end{tabular}

$* \mathrm{p}<0.05$ significantly different from the normal subjects.

** $\mathrm{p}<0.05$ significantly different from the normal subjects and the patients with alcoholic cirrhosis.

Tab. 3. Serum protein concentrations $(\mathrm{g} / \mathrm{l})$ before and six to twelve months following an interposition meso-caval shunt in ten cirrhotic patients. Median and range.

\begin{tabular}{|c|c|c|}
\hline & Before & After \\
\hline Prealbumin & $0.09(0.03-0.12)$ & $0.14(0.06-0.20)$ \\
\hline Albumin & $33 \quad(17 \quad-36)$ & $\left.\begin{array}{lll}38 & (31 & -42\end{array}\right)$ \\
\hline$\alpha_{1}$-Antiproteinase & $2.1(1.0-3.6)$ & $1.7(1.0-2.1)^{*}$ \\
\hline Orosomucoid & $0.6(0.4-1.2)$ & $(0.2-0.8)^{*}$ \\
\hline Haptoglobin & $0.7 \quad(0.1-1.6)$ & $(0.1-0.8)^{*}$ \\
\hline Caeruloplasmin & $0.4 \quad(0.2-0.6)$ & $0.3 \quad(0.2-0.4)^{*}$ \\
\hline IgG & $20.7(13.0-29.6)$ & $18.7(10.6-31.3)$ \\
\hline IgA & $3.80(2.30-6.20)$ & $3.54(1.90-7.25)$ \\
\hline IgM & $1.90(0.40-4.00)$ & $1.50(0.85-3.70)$ \\
\hline
\end{tabular}

$* \dot{\mathrm{p}}<0.05$

It has been postulated that the hypergammaglobulinaemia in liver cirrhosis is caused either by immunization with gut-derived antigens which bypass the liver, or by a generalized immunologic hyperreactivity $(13,14)$. The "giut antigen concept" implies that a further increase of serum immunoglobulins should occür following shunt surgery. This is, however, not found in our study, but Prytz et al. in a larger group of patients with mainly porto-caval shunts described a small but significant increase 7-9 weeks postoperatively (14). The differences between the studies might be explained by the different sizes of the study groups, different postoperative time intervals and also by different types of shunts. Engelbrecht et al. found in rats that animals with a porto-caval shunt had a highly significant rise in $\gamma$-globulins, while rats with a meso-caval shunt exhibited no $\gamma$-globulin changes. The authors proposed a liver mechanism regulating splenic globulin production which is preserved following a meso-caval shunt (15).

In conclusion, we find that a meso-caval shunt in cirrhotic patients does not produce profound changes in serum prealbumin, albumin and immunoglobulin concentrations, whereas all the acute phase reactants studied are significantly depressed. 


\section{References}

1. Hällen, J. \& Laurell, C. B. (1972) Scand. J. Clin. Lab. Invest. 29 (suppl 124), 97-103.

2. Skrede, S., Blomhoff, J. P., Elgjo, K. \& Gjone, E. (1975) Scand J. Clin. Lab. Invest. 35, 399 - 406.

3. Christensen, E., Schlichting, P., Fauerholdt, L., Juhl, E.; Poulsen, H., Tygstrup, N. \& The Copenhagen Study Group for Liver Diseases (1985) Hepatology 5, 843-853.

4. Rueff, B., Degos, F. \& Degos, J. D. (1976) Lancet 1, 655659.

5. Nosslin, B. (1960) Scand. J. Clin. Lab. Invest. 12 (suppl 49), 54.

6. Scandinavian Committee on Enzymes (1974) Scand. J. Clin. Lab. Invest. 33, $291-306$.

7. Scandinavian Committee on Enzymes (1981) Scand. J. Clin. Lab. Invest. 41, 107-116.

8. Laurell, C. B. (1972) Scand. J. Clin. Lab. Invest. 29 (suppl 124), $21-37$.

9. Carlsson, J. \& Eriksson, S. (1980) Acta. Med. Scand. 207, 79-83.

10. Cooksley, W. G. E., Powell, L. W. \& Halliday, J. W. (1973) Brit. J. Haematol. 25, 147-164.

11. Dinarello, C. A. (1984) Surv. Immupol. Res. 3, 29-33.

12. Sakamoto, S., Koga, S. \& Ibayashi, H. (1984) HepatoGastroenterology $31,248-253$.

13. Stobo, J. D. (1979) Dig. Dis. Sci. 24, 737-740.

14. Prytz, H., Björneboe, M., Staehr Johansen, T. \& Örskov, F. (1974) Acta. Med. Scand. 196, 109-112.

15. Engelbrecht, G. H. C., van Hoorn-Hickman, R., Keraan, M. \& Meyers, O. L. (1981) Dig. Dis. Sci. 26, 1100-1103.

\author{
B. Hultberg \\ Department of Clinical Chemistry \\ University Hospital \\ S-221 85 Lund
}

